\section{New Astronomer Royal for Scotland}

\section{by John Gribbin}

THE announcement that Dr V. C. Reddish is to succeed Professor $\mathbf{H}$. Brück as Astronomer Royal for Scotland and Director of the Royal Observatory, Edinburgh (ROE) comes as no surprise to astronomers. Dr Reddish's new post is one of the two key jobs in the rebuilding of British optical astronomy (sec Nature, 251, 456; 1974). The Royal Greenwich Observatory (RGO), under the Directorship of Professor F. G. Smith, will have responsibility for running the new Northern Hemisphere Observatory, whereas the ROE provides the base in the United Kingdom for the Science Research Council (SRC) team running the 48inch Schmidt Camera at Siding Spring and also plays a large part in the Anglo-Australian Telescope project. In addition, the ROE has the responsibility of setting up the $3.8-\mathrm{m}$ infrared flux collector which is to be built in Hawaii with SRC funds (see Nature, 250, 617; 1974). So the responsibility for the hardware of what Professor Smith sees as a new 'Golden Age' of astronomy is divided evenly between Britain's two principal optical observatories.

Like Professor Smith at the RGO, Dr Reddish seems well qualified for the

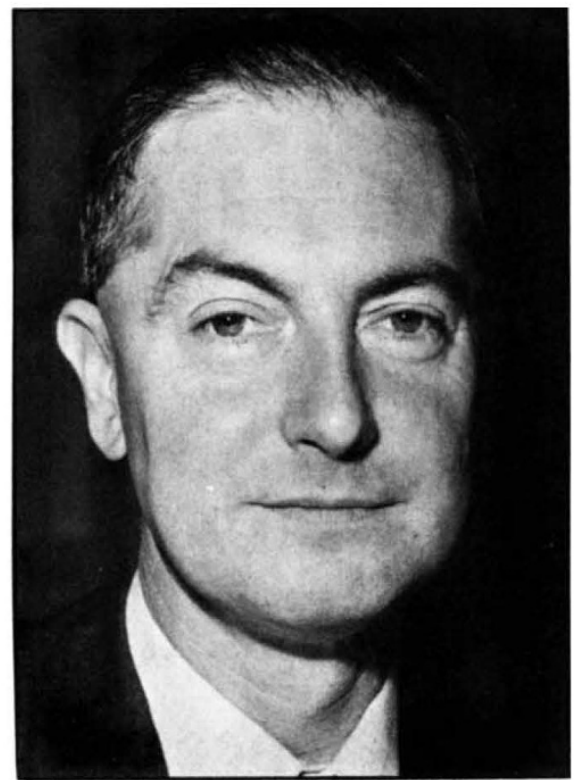

task. His experience is rather more diverse that that of most academics, embracing 12 months in a brewery, threc years in a bank and three years in the Royal Navy before he took his first degree. Since gaining his $\mathrm{PhD}$ as a member of University College, London, in 1954 Dr Reddish has been based in Edinburgh except for three years from 1959, which he spent at Jodrell Bank.

He says that those three years were of great importance since they introduced him to the teamwork approach used by radio astronomers; with the electronic equipment attached to telescopes becoming ever more sophisticated there is now very little difference between the tasks of observers at radio, optical and other frequencies, and Dr Reddish realised from his experience at Jodrell Bank that modern astronomers would have to follow the same path of collaboration in order to get the best results out of their new instruments.

Since 1962 Dr Reddish has worked from time to time as a visitor at Hamburg, in the United States and in Australia; he was Project Officer for the construction of the United Kingdom Schmidt in Australia, and serves at present as one of three British members on the AAT Board. It is interesting that the future of British optical astronomy is largely in the hands of one man who has 'converted' from radio astronomy, and another who says that he learnt a great deal from his three years at Jodrell Bank. But divisions between observers today mean very little, and the real importance of both these appointments is that the men concerned have the proven administrative experience, as well as appropriate scientific pedigrees, to ensure that full advantage is taken of the opportunity now presented to British astronomy.
THE Soviet Mars mission of 1973--74 was only a partial success, with one intended satellite (Mars 4) and one landing craft (Mars 7) overshooting the planet. Results of the data from the more successful probes (Zemlya $i$ Vselennaya, No. 5, 7-11; 1974), although scientifically stimulating, may well give certain embarrassment to Soviet politicians, for-in spite of their predilections for the colourthe red planet is, in fact, not quite as red as it has previously been painted.

According to the colour photographs received from the orbiting Mars 5 (and from the overshooting Mars 4), the craters in particular reveal significant variations of colour. Some of them exhibit a blue-green tint, contrasting sharply with the general orange background of the crater bottom. "If the correctness of the colour transmission is confirmed", says the report with some caution, "this may indicate that the bottoms of these craters are composed of rock different from that on the surface". Or (even more cautiously) "maybe, after all, there still exists vegetation on Mars?"

Passing quickly from these speculations, however, the report states a number of quantitative facts: the

\section{The not

so red planet

from Vera Rich

argon content of the Martian atmosphere (according to mass spectroscopy measurements from Mars 6) has the very high value of $35 \pm 10 \%$ -a result at present inexplicable, although relative argon enrichment of the atmosphere as a result of the freezing of $\mathrm{CO}_{2}$ to form the polar caps has been postulated tentatively.

The amount of water vapour in the Martian atmosphere was found to be much higher than measured by Mars 3 and at places the amount of precipitated water reached $60-70 \mu \mathrm{m}$, some 3-5 times higher than the values obtained from the Mars 3 data of 2 years ago. The distribution of this moisture over the surfacs of the planet was found to be irregular. The joint Franco-Soviet polarimetry experiment gave results far lower than expected, the greatest polarisation (up to 10\%-some 2-3 times less than that of the Moon)-being observed close to the northern extremity of the Argyre crater sea.

Infrared measurements gave surface temperatures very close to the theoretical models for highly fragmented rock; the highest temperature recorded being $272 \mathrm{~K}$, corresponding to $1300 \mathrm{~h}$ local time. Correlation of surface temperature and relief has still not been observed.

Photography of the topographical features, apart from the curious problem of colour, has produced interesting results. With the high resolution used (down to tenths of a kilometre), the existence of two forms of crater was established: large craters having a flat bottom and slopes considerably affected by wind erosion, and small cup-shaped craters.

For a mission only partially successful in its hardware, the Soviet Mars survey of 1973-74 has not been unrewarding. Perhaps, however, the most significant data recorded are those from the analysis of the phase variation of the radio signals from the probes. From this it has been cstimated that the electron concentration in the Martian ionosphere is $6 \times 10^{3}$ electrons per centimetre at night and $1.5 \times 10^{5}$ electrons per centimetre by day. It seems likely that on the basis of these figures, future Mars probes will use wavelengths longer than $500-1,000 \mathrm{~m}$ for radio communication. 